(3)

Volume 20, 2017

\title{
ACCEPTANCE OF ERP SYSTEMS: THE USES AND Gratifications Theory PERSPECTIVE
}

\author{
Bassam Hasan \\ University of Toledo \\ bhasan@utoledo.edu \\ Toledo, OH, USA
}

\begin{abstract}
\end{abstract}
Aim/Purpose

\begin{abstract}
This study aims to provide a better understanding of individual acceptance of enterprise resource (ERP) systems. Based on the uses and gratifications theory (UGT) and informing science theory, the study developed and empirically tested a research model to explain the effects of ERP characteristics (specifically, informativeness and enjoyment) on ERP acceptance and use.

Background Individual acceptance of ERP systems is crucial for achieving the benefits associated with ERP systems. Unfortunately, little research has focused on acceptance of ERP systems at the individual level. This study attempts to fill this void.
\end{abstract}

Methodology A survey questionnaire was distributed to ERP users to collect data to empirically test the research model developed in this study. In addition to demographic and background information question, the survey contained instruments to measure the study variables.

Contribution The empirical results show that UGT provides a sound theoretical framework for explaining users' gratifications, attitudes, and behavioral intentions toward adopting and using an ERP. These results support the view that subsumes information systems and other fields that endeavor to inform their audience.

Findings Individuals' perceptions of the informativeness and entertainment of ERP systems demonstrated strong direct effects on attitude toward using and satisfaction with ERP systems. In turn, satisfaction with ERP systems showed a direct significant impact on intention to use an ERP system.

Recommendations Maintaining a favorable environment and designing training workshops that for Practitioners highlight the information and enjoyment aspects of an ERP can boost users' perceptions of ERP informativeness and enjoyment and, eventually, improve their attitude and satisfaction with an ERP.

Recommendation Researchers should test the proposed research model with other types of ERP for Researchers systems and in different environments to enhance the generalizability of the results to other systems and settings.

Accepting Editor Kay Fielden | Received: July 9, 2017| Revised: October 19, November 2, November 13, December 12, 2017 | Accepted: December 14, 2017.

Cite as: Hasan, B. (2017). Acceptance of ERP systems: The uses and gratifications theory perspective. Informing Science: the International Journal of an Emerging Transdiscipline, 20, 259-275. https://doi.org/10.28945/3905

(CC BY-NC 4.0) This article is licensed to you under a Creative Commons Attribution-NonCommercial 4.0 International License. When you copy and redistribute this paper in full or in part, you need to provide proper attribution to it to ensure that others can later locate this work (and to ensure that others do not accuse you of plagiarism). You may (and we encourage you to) adapt, remix, transform, and build upon the material for any non-commercial purposes. This license does not permit you to use this material for commercial purposes. 
ERP Acceptance: UGT Perspective

Impact on Society The results of is study can be used as a foundation on which to develop plans and design strategies to enhance individual acceptance of ERP systems and realize the benefits associated with these systems.

Future Research Future research should extend the research model by integrating other personal and technology variables to provide further insights into what influences individuals to accept or reject an ERP system.

Keywords enterprise resource system (ERP), uses and gratification theory (UGT), informativeness, enjoyment, attitude, satisfaction, intention to use ERP systems

\section{INTRODUCTION}

While Enterprise Resource Planning (ERP) systems are diverse and come in different capabilities and sizes, they refer to organization-wide integrated information systems that are used to improve the efficiency and effectiveness of business processes by capturing real time business data and providing accurate, timely, and consolidated data throughout the organization (Saadé, Nijher, \& Sharma, 2017). The implementation and use of enterprise resource planning (ERP) systems as tools to gain valuable operational and competitive advantages is on the rise across businesses. The main benefits of ERP systems include enhancing decision-making, streamlining operations, accelerating fulfillment of customer orders, improving information visibility, flow, and accessibility throughout the business. When ERP systems are fully-utilized, they can increase employees' productivity and organizational efficiency and effectiveness (Coulson, Olfman, Ryan, \& Shayo, 2010; Ram, Corkindale, \& Wu, 2013; Zabukovsek \& Bobek, 2013). Unfortunately, the organizational adoption and implementation of ERP systems do not automatically guarantee the desired improvements in business competitiveness. The literature is rife with examples of ERP implementations that ended up in total failure and resulted in substantial losses of organizational resources (Saadé et al., 2017).

While the causes of ERP failures are numerous, most failures and variations in the success rates of ERP implementations have been linked to the extent to which users are willing to accept and use these systems (Hwang \& Grant, 2011). Thus, individual characteristics, attitudes, and behavioral intentions of the users who are expected to use those systems are critical to the utilization and success of ERP systems (Shih, 2006). Similarly, users' perceptions of an ERP system can have a great impact on the degree to which the ERP implementation efforts succeed or fail (Abdinnour-Helm, LengnickHall, \& Lengnick-Hall, 2003; Hwang \& Grant, 2011; Longinidis \& Gotzamani, 2009). Consequently, the lack of users' acceptance and under-utilization of ERP systems have been consistently identified as key factors contributing to the failure of ERP implementations and the inability of businesses to recoup the investments that were made in these systems (Nah, Tan, \& Teh, 2004). Therefore, researchers have consistently called for increased attention to individual and behavioral factors that can boost or hamper users' perceptions and acceptance and utilization of ERP systems.

Despite the substantial and still growing body of literature on users' acceptance and utilization of ERP systems, the causes of ERP under-utilization and failure are still poorly understood (Calisir \& Calisir, 2004; Ram et al., 2013; Shih, 2006). Moreover, the majority of past ERP acceptance studies have relied heavily on the technology acceptance model (TAM) (Davis, 1989) as a theoretical framework (e.g. Garača, 2011; Mayeh, Ramayah, \& Mishra, 2016; Zabukovsek \& Bobek, 2013). While past studies provide valuable insights into understanding users' ERP acceptance, other factors and theoretical frameworks might offer valuable insights into users' perceptions of ERP systems (Hwang \& Grant, 2011; Nah et al., 2004). Thus, research aimed offering new insights to understanding users' acceptance and adoption of ERP systems is vital for understanding and improving ERP success.

To address the two limitations described above, the present study attempts to achieve two goals. First, this study extends past research by focusing on additional variables that were not addressed in previous research in an attempt to enhance understanding of intrinsic motivations that attract users 
to adopting and using ERP systems. Second, this study digress from past studies by using marketing and communication theories to develop and empirically test a model of factors affecting individuals' adoption and utilization of ERP systems. The proposed model in this study incorporates constructs from the Uses and Gratification Theory (UTG) (Blumler \& Katz, 1974) as determinants of users' perceptions about ERP systems. The UTG offers a sound theoretical framework for studying the use of ERP systems and was successfully used to modern technologies such as Twitter (Alajmi, Alharbi, \& Ghuloum, 2016). Certainly, a better understanding of the gratifications and intrinsic factors that stimulate or discourage users to use ERP systems provides valuable contributions to the design of more effective ERP systems that can maximize users' gratifications and sway them to use these systems (Hwang, 2012).

\section{THEORETICAL BACKGROUND}

In the quest to identify and understand the behavioral, cognitive, and motivational factors that affect users' decisions to accept and use an ERP, past studies have applied a host of theories to explain ERP adoption and utilization. The technology acceptance model (TAM) (Davis, 1989) has been used extensively in ERP literature to provide theoretical basis to investigate behavioral aspects of ERP adoption and use by end-users. Table 1 presents a partial list of studies that have utilized TAM in investigating users' acceptance of ERP systems. While TAM has explained ERP acceptance across multiple studies, other studies suggest that TAM's main constructs (i.e., perceived ease of use and perceived usefulness) cannot sufficiently explain ERP acceptance (Nah et al., 2004).

Table 1: Studies of ERP acceptance that used TAM

\begin{tabular}{|l|l|}
\hline \multicolumn{1}{|c|}{ STUDY } & FACTORS EXAMINED \\
\hline Al-Jabri \& Roztocki (2015) & $\begin{array}{l}\text { Information transparency, perceived usefulness, perceived ease } \\
\text { of use, perceived compatibility, perceived fit, attitude toward } \\
\text { using ERP. }\end{array}$ \\
\hline Amoako-Gyampah \& Salam (2004) & $\begin{array}{l}\text { Training, communication, perceived usefulness, perceived ease } \\
\text { of use. }\end{array}$ \\
\hline Amoako-Gyampah (2007) & $\begin{array}{l}\text { Perceived usefulness; ease of use; user involvement, manage- } \\
\text { ment support. }\end{array}$ \\
\hline Bueno \& Salmeron (2008). & $\begin{array}{l}\text { Top management support, communication, cooperation, train- } \\
\text { ing and technological complexity. }\end{array}$ \\
\hline Calisir \& Calisir (2004) & $\begin{array}{l}\text { Perceived usefulness, perceived ease of use, learnability, sys- } \\
\text { tem capability, user guidance. }\end{array}$ \\
\hline Garača (2011) & Computer anxiety, perceived usefulness, perceived ease of use \\
\hline Hwang \& Grant (2011) & $\begin{array}{l}\text { Power distance, uncertainty avoidance, computer self-efficacy, } \\
\text { perceived ease of use. }\end{array}$ \\
\hline Mayeh, Ramayah, \& Mishra (2016) & Absorptive capacity, communication and trust. \\
\hline Nah, Tan, \& Teh (2004) & $\begin{array}{l}\text { Perceived usefulness, perceived ease of use, perceived compat- } \\
\text { ibility, perceived fit, attitude toward using ERP. }\end{array}$ \\
\hline Scott (2008) & $\begin{array}{l}\text { Computer self-efficacy, perceived ease of use, perceived use- } \\
\text { fulness, perceived usability. }\end{array}$ \\
\hline Shih \& Huang (2009) & $\begin{array}{l}\text { Top management support, computer self-efficacy, computer } \\
\text { anxiety, perceived ease of use, perceived usefulness. }\end{array}$ \\
\hline Sternad, Gradisar, \& Bobek (2011) & $\begin{array}{l}\text { Organizational, system and personal characteristics, perceived } \\
\text { usefulness, perceived ease of use, attitude. }\end{array}$ \\
\hline Zabukovsek \& Bobek (2013) & $\begin{array}{l}\text { Work compatibility, organizational-process, system, and per- } \\
\text { sonal characteristics. }\end{array}$ \\
\hline
\end{tabular}


Whereas much research has examined behavioral factors influencing acceptance of ERP systems (Mitra \& Mishra, 2016), most of the theories used in past research were not able to fully explain endusers' ERP acceptance (Al-Jabri \& Roztocki, 2015). Hence, some researchers pointed out a need to consider other theories from other research areas to provide new insights into users' acceptance of ERP. For example, Aladwani (2001) argues that applying marketing concepts to ERP implementation could help overcome users' resistance to ERP. Garača (2011) utilized the Expectation Confirmation Theory (ECT) from marketing research to examine acceptance of ERP systems. Since ERP systems are implemented to enhance and simplify integration of business processes, data, and communication within and across business units (Hwang \& Grant, 2011), the Uses and Gratification Theory, which was formulated to understand customers' selection of a particular communication media, as explained below, is well suited for studying the motivational factors affecting individual adoption of ERP systems.

\section{USES AND GRATIFICATIONS THEORY}

The uses and gratification theory (UGT) (Blumier \& Katz, 1974) suggests that consumers play an active role in selecting and using a particular media. According to UGT, consumers actively evaluate the available media and they select the media or innovation that they believe will satisfy their needs and maximize their gratification. The UGT regards individuals as agents who perform different actions based on the needs that they expect to satisfy from using a certain medium (Alajmi et al., 2016). In other words, UGT focuses on the motives for specific types of usage, and the satisfaction individuals obtain from such use. In particular, UGT posits that people seek to use a media or innovation which provides them with the maximum information and enjoyment (M. M. Luo \& Remus, 2014; Shao, 2009). This suggests that information and enjoyment play a pivotal role in people's choice of a media or innovation. Accordingly, users will be more motivated to use an innovation when they believe that the innovation will provide them with enjoyment and satisfy their information needs.

Past research had utilized UGT to study consumers' motivations and hesitations for using older and traditional media such as radio, TV, and print media (Eighmey \& McCord 1998). More recently, UGT has been successfully used to understand and explain the acceptance and use of various modern communication and computer technologies such as the Internet (Stafford, Stafford, \& Schkade, 2004), mobile phones (North, Johnston, \& Ophoff, 2014), social media (Petersen \& Johnston, 2015), Twitter (Alajmi et al, 2016), user-generated media such as youtube (Shao, 2009), and online games (Wu, Wang, \& Tsai, 2010). Similarly, UGT was used as a theoretical basis for understanding why people prefer to use a specific computer-meditated communication media such as social networking sites, instant messaging, and email (Chen, 2011, Ku, Chu, \& Tseng, 2013; Leung, 2013; Lim, \& Ting, 2012). UGT compares well with other models used in the literature to understand and explain users' motivations to adopt and utilize various information technologies (Alajmi et al., 2016). For example, M. M. Luo and Remus (2014) found that UGT provides specific information and better understanding of usage than other models of information systems acceptance.

This study also utilizes the informing science theory (Cohen, 2009). The aim of informing science is to inform the clients with proper information to maximize their effectiveness. The informing science theory explains users' acceptance and use of a technology in terms of the extent to which a technology provides its clients with the information they need to increase their effectiveness. Past research suggests that the informing environment is a dynamic one and operates at three levels of abstraction: (a) the instance of being informed by an existing system; (b) the creation of new instances of informing; and (c) the creation of new designs for informing (Cohen, 1999; Koh, Prybutok, Ryan, \& Wu, 2010). Thus, the key factor that attracts clients to a system is the ability of the system to provide its clients with the information they need to perform their tasks successfully. That is, "the ultimate goal of information systems is to enhance the effectiveness of the informed" (Koh et al., 2010, p. 179) by providing needed, accurate, and usable information. 


\section{RESEARCH MODEL}

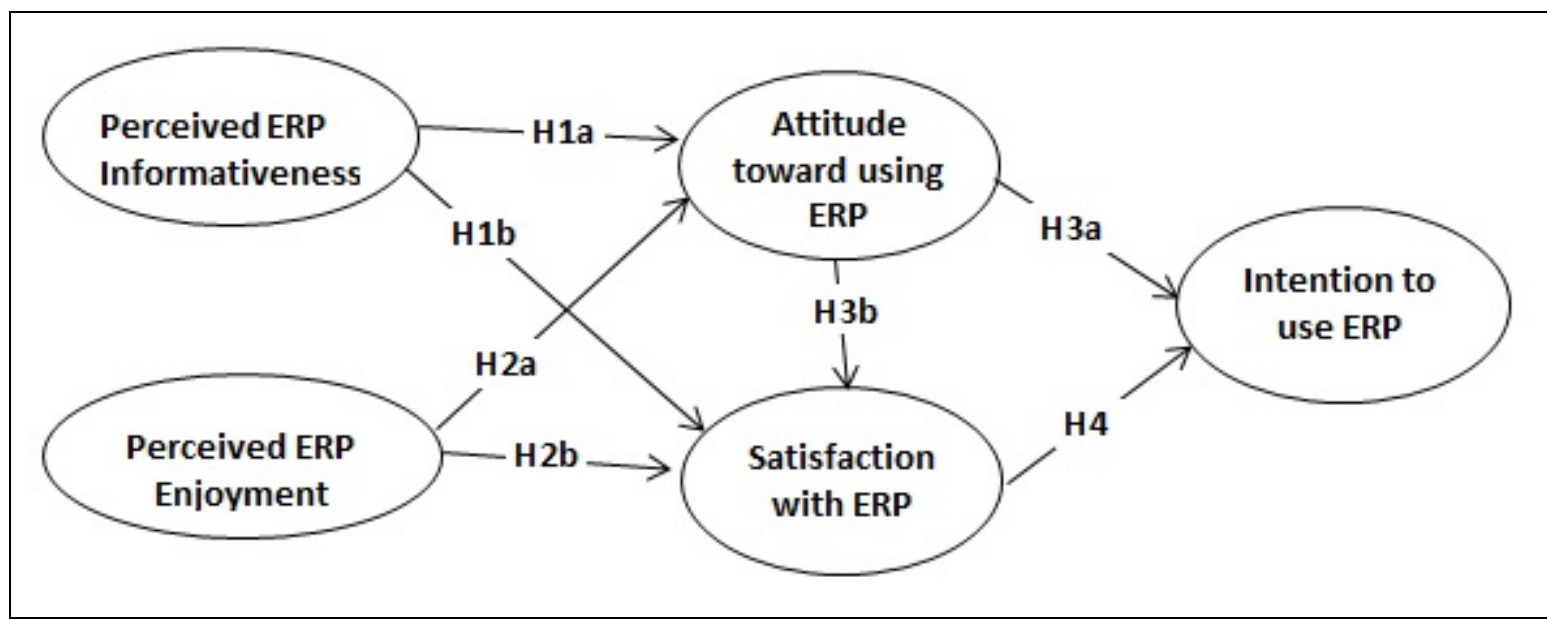

Figure 1. Research model

Figure 1 presents the research model guiding the present study. As Figure 1 shows, the research model posits that two key variables in the UGT, namely enjoyment and informativeness (Ruggiero, 2000; Stafford et al., 2004) are hypothesized to have direct effects on ERP attitude and satisfaction with ERP, which are considered two key determinants in end-users' acceptance of ERP systems. Then attitude and satisfaction with ERP are hypothesized to be direct determinants in users' intention to adopt and use an ERP system (Abdinnour-Helm et al., 2003). The research variables and the hypothesized relationships among the research constructs are explained below.

\section{INFORMATIVENESS}

Informativeness, which refers to the extent to which a media provides its users with helpful and useable information, is a key construct in the UGT (X. Luo, 2002). The need for information is considered a key pillar in the informing science theory (Cohen, 2009). Koh et al. (2010) suggest that a system's ability to provide its user the information they need represents the first-level informing instance of the information science theory. They also argue that employees' mandated use of information systems does not guarantee achieving the benefits associated with the systems. On the contrary, employees must be properly informed by the system and be able to trust information they obtain from the system are prerequisites for achieving the desired outcomes of the system. Thus, users' perceptions about the informativeness of a system represent a major antecedent to the acceptance and use of that system.

Alajmi et al. (2016) found the need for information was a key and significant predictor of Twitter use. Thus, ERP informativeness can be defined as the extent to which an ERP system provides its users with the information they need to complete their job activities. As noted earlier, businesses implement ERP systems not only to replace the fragmented legacy systems dispersed throughout their organizational units, but also to consolidate all business data from disconnected databases into a central database to improve delivery of critical information to users, improve data consistency, and increases visibility of corporate data (Ram et al., 2013; Somers, Nelson, \& Karimi, 2003). Based on the notion that the need for information drives peoples' use of a technology (Alajmi et al., 2016), the extent to which an ERP system can fulfill the information needs of its users is critical to the success of an ERP system.

Several constructs similar to informativeness have been widely used in past ERP acceptance research. For instance, Al-Jabri and Roztocki (2015) examined the impact of information transparency, i.e., openness and access to information, on perceived ease of use, perceived usefulness, and attitude to- 
ward ERP use. They argue that information transparency prevails when employees have access to all internal and external information required to perform their work duties and responsibilities. Their results showed that perceived information transparency had significant direct effects on perceptions of usefulness and ease of use, and indirect effect on attitude toward ERP use. They suggest that the amount and quality of information that an ERP system makes available to its users can satisfy their information needs and improve their attitude toward ERP. Hsu, Yen, and Chung (2015) examined the impact of information quality on ERP use in the post-implementation phase. Their results showed that information quality was a key determinant of ERP acceptance and use.

User satisfaction in ERP implementation projects had been frequently used as an indicator of ERP use and success. Somers et al. (2003) defined user satisfaction in information systems environments as the extent to which users believe that the system available to them meets their information requirements. McHaney, Hightower, and Pearson (2002) suggest that when a system meets information needs of its users, it strengthens satisfaction with the system and, conversely, users will be dissatisfied with the system if it does not provide the information they need. With respect to ERP systems, Longinidis and Gotzamani (2009) maintain that an ERP that provides helpful and accurate information increases users' satisfaction. Finally, information quality has demonstrated strong influence on user acceptance, system use, and user satisfaction and contributes to shaping the users intention to use ERP systems (Ram et al., 2013). As noted above, the research by Hsu et al. (2015) revealed that information quality had significant positive effects on satisfaction with ERP system. Hence, the following two hypotheses are suggested.

H1a: Perceived informativeness of an ERP system will have a direct impact on attitude toward the ERP system.

H1b: Perceived informativeness of an ERP system will have a direct impact on satisfaction with the ERP system.

\section{ENJOYMENT}

UGT posits that enjoyment or entertainment represents a major gratification that users seek to fulfill and maximize from adopting and using a certain medium. In a recent study that used UGT to examine Twitter use, Alajmi et al. (2016) found that enjoyment (i.e., the need to pass time) had a significant impact on individuals' use of 'Twitter. Enjoyment is a key construct in IS literature that has been associated with the acceptance of various technologies. For example, Mun and Hwang (2003) examined the impact of enjoyment on acceptance of a web-based learning system and found that perceived enjoyment had significant effects on perceived usefulness, perceived ease of use, and web selfefficacy. Constructs like perceived entertainment (Luo, 2002) and playfulness (Webster \& Martocchio, 1992) have been used in the literature to refer to the same concept of hedonic or intrinsic motivation to using ERP systems (Hwang, 2012). Enjoyment has been used as a dimension of playfulness and demonstrated strong impact on attitude to use social media sites (Hung, Tsai, \& Chou, 2016).

Enjoyment from using a system refers to the extent to which the activity of using the system is perceived to be enjoyable by itself and aside from any expected benefits or outcomes (Davis, Bagozzi, \& Warsaw, 1992). ERP enjoyment gratification can be defined as the fun or entertainment that a user gets from using an ERP system. For instance, users of an ERP system may experience enjoyment from using comprehensive system with standard interface which they can use to perform all the job activities. In addition, users' might enjoy using an ERP system because it eliminates multiple data entries and also reduces duplicate work (Amoake-Gyampah, 2007). Hwang (2012) maintains that perceived enjoyment is a very influential factor that should be considered in examining users' acceptance of ERP systems.

In a study by Al-Gahtani and King (1999), perceived enjoyment demonstrated significant effects on end-user satisfaction and attitude toward using information systems. Fagan, Neill, and Wooldridge (2008) examined perceived enjoyment as a direct determinant of intrinsic motivations (usefulness and ease of use) to use a system. Their results showed significant relationships between enjoyment 
and perceived usefulness and ease of use. Mun and Hwang (2003) explain that a sense of enjoyment in using a given system should reduce users' anxiety and help them feel confident about their ability to successfully execute the required usage actions. Hwang (2012) found the perceived enjoyment of using an ERP system had a significant impact on intention to use the ERP system. His results also showed that the impact of enjoyment on intention to use an ERP was much stronger than that of personal innovativeness in IT. Thus, the following hypotheses are proposed.

H2a: Perceived enjoyment of using an ERP system will have a direct impact on attitude toward the ERP system. H2b: Perceived enjoyment of using an ERP system will have a direct impact on satisfaction with the ERP system.

\section{ATTITUDE}

Attitude refers to an individual's tendency to respond in a favorable or unfavorable manner to an object or behavior (Ajzen \& Fishbein, 1980; Fishbein \& Ajzen, 1975). Attitude is a central concept in the theory of reasoned action (TRA), which suggests that attitude towards a behavior is a key determinant of performing that behavior in the future. TRA maintains that people form their attitudes toward a behavior based on their experience with the behavior or their understanding of the consequences of performing that behavior. In the context of IS use, attitude toward use can be defined as the tendency of users to respond in a favorable or unfavorable manner to an IS, application, IS staff person, or a process related to the use of a system or application (Melone, 1990). Numerous studies in the information systems literature utilized attitude as a key determinant of systems' usage behaviors (Al-Jabri \& Roztocki, 2015).

In ERP settings, users' attitudes toward ERP systems are pivotal to the success of ERP implementation (Abdinnour-Helm et al., 2003). Garača (2011) argues that the attitude (positive or negative) that users form toward the ERP system affects the organization's ability to reap the benefits associated with ERP systems. Across multiple studies, the attitude construct has mediated the relationship between external variables and ERP acceptance and use. For example, attitude toward ERP mediated the effects of perceived ease of use and usefulness of ERP systems on ERP use (Al-Jabri \& Roztocki, 2015). Nah et al. (2004) maintain that users of ERP systems form their attitude based on their initial interacting with the system. Then their attitude affects the amount or quality of system usage, which can impact their productivity, job satisfaction, and loyalty to toward the organization. Finally, attitude toward ERP systems demonstrated a strong direct impact on intention to use an ERP across multiple empirical studies (e.g. Al-Jabri \& Roztocki, 2015; Amoako-Gyampah \& Salam, 2004). Thus, the following two hypotheses are suggested.

H3a: Attitude toward using an ERP system will have a direct impact on intention to use the ERP system.

H3b: Attitude toward using an ERP system will have a direct impact on satisfaction with the ERP system.

\section{SATISFACTION}

As a psychological construct, the concept of satisfaction is widely used in various behavioral contexts such as job satisfaction, satisfaction with product or service, and satisfaction of users with information system use (Garača, 2011). Doll and Torkzadeh (1988) define end-user satisfaction as the affective attitude towards a specific computer application by someone who interacts with the application directly. Satisfaction represents an individual's emotional state following first-hand experience with the target object or behavior (Premkumar \& Bhattacherjee, 2008). End-user satisfaction with IS has been extensively used in the literature as a measure or proxy for information systems success.

Longinidis and Gotzamani (2009) maintain that ERP systems do not automatically achieve success or competitive gains. They suggest that user satisfaction is a key predecessor to ERP systems' ultimate success. Furthermore, satisfaction with ERP system had been used as a surrogate measure of ERP success and a requisite for the realization of benefits of ERP systems (Somers et al., 2003). Garača 
(2011) applied TAM to a model of ERP acceptance and found that perceived ease of use and perceived usefulness demonstrated significant effects of satisfaction with ERP system, which in turn demonstrated a significant impact on ERP acceptance and use. In ERP contexts, user satisfaction has been based on a system's ability to provide complete, accurate, and timely information to its users (Amoake-Gyampah, 2007). Therefore, the following hypothesis is suggested.

H4: Satisfaction with an ERP system will have a direct impact on intention to use the ERP system.

\section{METHODOLOGY}

\section{PARTICIPANTS AND PROCEDURE}

The research survey for this study was distributed to 134 students enrolled in graduate business courses at a four-year public university in the Midwest. After providing demographic data, the participants were asked whether they have used or still using an ERP system in the jobs. Those who indicated that they have not used an ERP system before were asked to stop and submit the survey and those who indicated that they used ERP systems were instructed to complete the research survey. Eight seven participants indicated that they used ERP and completed the survey. About $40 \%$ were females $(n=35)$ and about $60 \%(n=52)$ were males. The age of participants ranged from 22 to 41 years with an average age of 25.4 years and a standard deviation of 4.8 years. Participants were employed in various industries such as retail, auto manufacturing, communication, healthcare, and education.

\section{MEASUREMENT}

Well operationalized and validated measures from previous studies were utilized to operationalize the variables examined in this study. ERP informativeness was measured by four items relating to the completeness, accuracy, format, and up-to-datedness of information obtained from the ERP system (Somers et al., 2003). A sample statement to measure informativeness is: "I believe that the information that I get from the ERP is complete". To measure perceived enjoyment, four statements from the work of Hwang (2012) and Davis et al. (1992) were adapted and used in this study. A sample statement from this scale is "I have fun using this ERP system". Response to informativeness and enjoyment statements were captured by a seven-point scale ranging from (1) strongly disagree to (7) strongly agree.

Four statements to measure attitude were adapted from the work of Al-Gahtani and King (1999). The statements asked individuals to indicate how they felt about using ERP systems. A sample statement of this measure is: "I feel that using an ERP system is a good idea". Satisfaction with the ERP was measured with four statements adapted from the work of Garača (2011) and Premkumar and Bhattaacherjee (2008). A sample statement from this scale is: "I am very satisfied with my use of this ERP system". Response attitude and satisfaction statements were recorded on a seven-point scale ranging from (1) strongly disagree to (7) strongly agree. ERP acceptance was assessed by evaluating the symbolic acceptance of the system. Symbolic acceptance, which refers to one's mental acceptance of an innovation, is most appropriate in mandatory use contexts such as that of ERP (Nah et al., 2004). The use of symbolic acceptance was further validated as a surrogate for ERP adoption in the study by Al-Jabri and Roztocki (2015). Thus, consistent with work and recommendations of Nah et al. (2004), behavioral intention was used assess ERP acceptance. The two statements to measure intention to use an ERP were (1) I intend to use an ERP system in the future and (2) I expect my future use of ERP system to continue.

\section{RESULTS}

Before testing the research hypotheses, a reliability and factor analysis were performed on all latent constructs shown in the research model. The results of the reliability and factor analysis are present- 
ed in Table 2. As can be seen in Table 2, all the measurement items demonstrated high loadings $(>0.70)$ on the constructs that they are intended to measure, and no item displayed a high loading on any unintended construct. In addition, the five instruments demonstrated high internal consistency reliabilities (Cronbach's alpha) and their alpha values ranged from 0.92 to 0.96 .

Table 2: Reliability and factor analysis

\begin{tabular}{|c|c|c|c|c|c|c|c|c|}
\hline CONSTRUCT & \#Items & Alpha & Item & 1 & 2 & 3 & 4 & 5 \\
\hline \multirow{4}{*}{ Informativeness } & \multirow{4}{*}{4} & \multirow{4}{*}{0.92} & Inf1 & 0.850 & & & & \\
\hline & & & Inf2 & 0.835 & & & & \\
\hline & & & Inf3 & 0.746 & & & & \\
\hline & & & Inf4 & 0.715 & & & & \\
\hline \multirow{4}{*}{ Entertainment } & \multirow{4}{*}{4} & \multirow{4}{*}{0.95} & Ent1 & & 0.850 & & & \\
\hline & & & Ent2 & & 0.835 & & & \\
\hline & & & Ent3 & & 0.746 & & & \\
\hline & & & Ent4 & & 0.715 & & & \\
\hline \multirow{4}{*}{ Attitude } & \multirow{4}{*}{4} & \multirow{4}{*}{0.96} & Att1 & & & 0.878 & & \\
\hline & & & Att2 & & & 0.899 & & \\
\hline & & & Att3 & & & 0.857 & & \\
\hline & & & Att4 & & & 0.837 & & \\
\hline \multirow{4}{*}{ Satisfaction } & \multirow{4}{*}{4} & \multirow{4}{*}{0.93} & Sat1 & & & & 0.714 & \\
\hline & & & Sat2 & & & & 0.744 & \\
\hline & & & Sat3 & & & & 0.799 & \\
\hline & & & Sat4 & & & & 0.773 & \\
\hline \multirow{2}{*}{ Intention } & \multirow{2}{*}{2} & \multirow{2}{*}{0.95} & Int1 & & & & & 0.697 \\
\hline & & & Int2 & & & & & 0.740 \\
\hline
\end{tabular}

Table 3 presents the correlation estimates among the study variables. As can be seen in Table 3, all the correlation coefficients ranged from 0.471 to 0.778 and were significant. Moreover, all the correlations estimates were below the 0.8 threshold to suspect the presence of multicollinearity among the variables (Bryman \& Cramer, 1994).

Table 3. Correlation matrix

\begin{tabular}{|l|c|c|c|c|c|}
\hline CONSTRUCT & $\begin{array}{c}\text { INFORMA- } \\
\text { TIVENESS }\end{array}$ & $\begin{array}{c}\text { ENTERTAIN- } \\
\text { MENT }\end{array}$ & $\begin{array}{c}\text { ATTI- } \\
\text { TUDE }\end{array}$ & $\begin{array}{c}\text { SATISFAC- } \\
\text { TION }\end{array}$ & $\begin{array}{c}\text { INTEN- } \\
\text { TION }\end{array}$ \\
\hline Informativeness & 1.00 & & & & \\
\hline Entertainment & $0.475^{* *}$ & 1.00 & & & \\
\hline Attitude & $0.611^{* *}$ & $0.489^{* *}$ & 1.00 & & \\
\hline Satisfaction & $0.644^{* *}$ & $0.778^{* *}$ & $0.655^{* *}$ & 1.00 & \\
\hline Intention & $0.471^{* *}$ & $0.762^{* *}$ & $0.560^{* *}$ & $0.724^{* *}$ & 1.00 \\
\hline
\end{tabular}

** $p<0.01$ 
Multiple regression analysis was used to test the research model and its hypothesized relationships. The first regression model assessed the impact of informativeness and entertainment on attitude toward using an ERP system. The results of this regression test are presented in Table 4. As Table 4 illustrates, the model was significant $(F=30.915, p=0.000)$ and showed that perceived informativeness $($ beta $=0.488, p=0.000)$ and perceived entertainment (beta $=0.257, p=0.008)$ had significant effects on attitude toward using an ERP system. The regression results also showed that the gratifications (informativeness and entertainment) variables explained about $41 \%$ of variability in ERP attitude. Thus, H1a and H1b were both supported.

Table 4. Regression results 1

\begin{tabular}{|c|c|c|c|c|c|c|c|}
\hline $\begin{array}{c}\text { DEPENDENT } \\
\text { VARIABLE }\end{array}$ & $\begin{array}{c}\text { PREDICTOR } \\
\text { VARIABLES }\end{array}$ & BETA & T & SIG & $\begin{array}{c}\text { ADJUSTED } \\
\text { R SQUARE }\end{array}$ & F & $\begin{array}{c}\text { SIG } \\
\text { F }\end{array}$ \\
\hline \multirow{2}{*}{ Attitude } & Informativeness & 0.488 & 5.187 & 0.000 & \multirow{2}{*}{0.410} & 30.915 & 0.000 \\
\cline { 2 - 9 } & Entertainment & 0.257 & 2.734 & 0.008 & & \\
\hline
\end{tabular}

The second regression analysis assed the effects of informativeness, entertainment, and attitude on satisfaction with ERP use. The results of this regression test are presented in Table 5. As Table 5 shows, the model was significant $(F=77.531, p=0.000)$ and revealed that perceived informativeness ( beta $=0.236, p=0.002$ ), perceived entertainment (beta $=0.548, p=0.000)$, and attitude (beta $=0.242$, $p=0.000$ ) had significant effects on satisfaction with ERP use. The three variables explained a sizable amount of about $73 \%$ of variability in satisfaction with ERP use. These results provide support for hypotheses $\mathrm{H} 2 \mathrm{a}, \mathrm{H} 2 \mathrm{~b}$, and $\mathrm{H} 2 \mathrm{c}$.

Table 5. Regression results 2

\begin{tabular}{|c|c|c|c|c|c|c|c|}
\hline $\begin{array}{c}\text { DEPENDENT } \\
\text { VARIABLE }\end{array}$ & $\begin{array}{c}\text { PREDICTOR } \\
\text { VARIABLES }\end{array}$ & $B E T A$ & $T$ & $S I G$ & $\begin{array}{l}\text { ADJUSTED } \\
R \text { SQUARE }\end{array}$ & $F$ & $S I G F$ \\
\hline \multirow{3}{*}{ Satisfaction } & Informativeness & 0.236 & 3.212 & 0.002 & \multirow{3}{*}{0.727} & \multirow{3}{*}{77.531} & \multirow{3}{*}{0.000} \\
\hline & Entertainment & 0.548 & 8.201 & 0.000 & & & \\
\hline & Attitude & 0.242 & 3.268 & 0.002 & & & \\
\hline
\end{tabular}

The last regression model evaluated the impact of attitude and satisfaction on intention to use an ERP system. The results for this model are presented in Table 6. As can be seen in Table 6, the model was significant $(F=48.783, p=0.000)$ and explained about $53 \%$ of the variability in intention to use an ERP. However, the results regarding the effects of the predictor variables were mixed. While the impact of satisfaction (beta $=0.625, p=0.000$ ) on intention to use ERP was significant, the impact of attitude on intention to use ERP was not significant (beta $=0.151, p=0.127$ ). Accordingly, the results provide support for $\mathrm{H} 4$ but not $\mathrm{H} 3$.

Table 6. Regression results 3

\begin{tabular}{|c|c|c|c|c|c|c|c|}
\hline $\begin{array}{c}\text { DEPENDENT } \\
\text { VARIABLE }\end{array}$ & $\begin{array}{c}\text { PREDICTOR } \\
\text { VARIABLES }\end{array}$ & BETA & T & SIG & $\begin{array}{c}\text { ADJUSTED } \\
\text { R SQUARE }\end{array}$ & F & SIG F \\
\hline \multirow{2}{*}{ Intention } & Attitude & 0.151 & 1.541 & 0.127 & \multirow{2}{*}{0.526} & 48.783 & \multirow{2}{*}{0.000} \\
\cline { 2 - 8 } & Satisfaction & 0.625 & 6.368 & 0.000 & & \\
\hline
\end{tabular}

\section{DISCUSSION AND IMPLICATIONS}

Organizations still face serious challenges in gaining competitive advantage or realizing the benefits associated with ERP systems. Some of these challenges relate to lack of users' motivation to fully 
adopt and utilize ERP systems. The present study aimed to enhance understanding of the intrinsic motivations that drive users to embrace or shun a new complex information technology such as an ERP system. To that end, based on theories of media and systems acceptance, this study developed and empirically tested a research model to gain better understanding of motivational factors affecting individual acceptance of ERP systems. The proposed model comprised four factors as direct and indirect antecedents to intention to use an ERP. Specifically, the research model posited that attitude toward using an ERP and satisfaction with ERP, which are directly influenced by perceived informativeness and perceived entertainment, are direct determinants of intention to accept and use an ERP. The overall results provide strong support for the research model and highlight the importance of the examined factors to ERP acceptance. Overall, the research model explained about $53 \%$ of the variability in intention to use an ERP system. This increased explanatory power represents an improvement over TAM-based models which typically explained about $40 \%$ of the variance in ERP usage intention and behavior (Nah et al., 2004). Thus, the proposed model yields better predictions of ERP acceptance and ultimate success.

As the research model shows, perceived informativeness and perceived entertainment are hypothesized to have direct effects on attitude toward using an ERP and satisfaction with an ERP system. The results show that these two factors explained about $41 \%$ of the variability in attitude toward using an ERP and about $73 \%$ of the variance in satisfaction with an ERP. These results are consistent with past studies which used UGT to examine the use of social media technologies such as Twitter (Alajmi et al., 2016). Furthermore, these results provide empirical support for the view that subsumes information systems and other fields that endeavor to inform their audience as suggested by informing science theory (Cohen, 1999). Recognizing that perceived informativeness and perceived entertainment are key constructs in the uses and gratification theory (UGT), these results provide strong support for utilizing UGT to better understand and explain factors that influence an individual's motivation to use an ERP system. Accordingly, this study successfully applied an important theoretical framework that had not been exploited in past ERP adoption research. Similarly, UGT has been recently applied to emerging technologies such as web-based systems, electronic-commerce, and social media. This study contributes to that line of research by applying the UGT to ERP acceptance and use.

In particular, perceived informativeness of an ERP system had significant positive effects on both attitude and satisfaction with an ERP. This finding reaffirms the value that users place on the information that they fetch from an ERP system and provides additional empirical support for the key role that information plays in ERP acceptance. These results provide empirical support for the informing science theory (Cohen, 2009) which states that the acceptance of a system is greatly impacted by the system's ability to provide its users with the proper information to maximize their effectiveness. A recent meta-analytic study and extensive review of critical success factors for ERP implementation by Zouine and Fenies (2014) found that information quality was among the major factors contributing to ERP success. However, other studies reported conflicting results. Ifinedo, Rapp, Ifinedo, \& Sundberg (2010) found that the impact of information quality on ERP success was not significant. One plausible explanation of this surprising finding may relate to the characteristics of the sample that was used in that study. The sample in the Ifinedo et al. (2010) study was composed of ERP users from numerous companies in two countries. Therefore, there is a great potential for intervening factors such as culture, managerial issues, or ERP environment (Hwang, 2012) to influence users' reactions to an ERP. Therefore, studies of ERP acceptance and success that utilize a homogenous sample using a single ERP system in the same environment might yield more accurate results and mitigate the impact of confounding factors that might influence research results.

While enjoyment has received little attention as a direct determinant of ERP acceptance, the results of this show that enjoyment has a strong and significant impact on both satisfaction with and attitude toward using an ERP system. This key finding corroborates past studies which found that the impact of enjoyment on some systems may be stronger than that of perceived usefulness and per- 
ceived ease of use (Hung et al., 2016). These findings are consistent with past research which used enjoyment as a variable affecting intrinsic motivation to use a system. For example, Fagan et al. (2008) found that perceived enjoyment demonstrated significant impact on perceived usefulness and perceived ease of use. Furthermore, Mun and Hwang (2003) hypothesized that perceived enjoyment would have direct effects on perceived usefulness and ease of use which in turn would have direct impact on intention to use and actual usage of web-based information systems. Their results provided significant support for their hypotheses and they concluded that enjoyment plays a substantial role usage intentions and acceptance behavior.

Whereas attitude and satisfaction explained about $53 \%$ of the variance in intention to use an ERP, the results regarding the significance of their effects were mixed. The results showed that impact of satisfaction with ERP on intention to use was significant and the impact of attitude toward an ERP was not. A plausible explanation for this unpredicted result may be that the effect of attitude was fully captured by satisfaction, especially that attitude demonstrated a strong positive impact on satisfaction with ERP. This finding is consistent with past research findings in similar environments. For instance, Garača (2011) found that satisfaction with ERP had a strong impact on intention to use an $\operatorname{ERP}($ beta $=0.64, p<0.01)$.

In addition to the implications discussed above, the results of this study offer valuable implications for businesses using or planning to use ERP systems. Past research has shown that in early stages of ERP deployment, users struggle to use an ERP system or understand how an ERP system can help them perform their job tasks (Hsu et al., 2015). Given that the participants in this study did not have extensive experience in ERP system use, the results of this study provide a better understanding of the factors that influence users' perceptions in the early stages of ERP usage. For instance, the results demonstrated that informativeness and entertainment had strong effects on determinants of ERP acceptance use. Thus, developing training material or workshops that highlight the amount and value of information that users can obtain from an ERP system can be very helpful to enhancing users' perceptions of ERP and increasing their acceptance of the system. Moreover, recent research suggests that user involvement in planning and executing the implementation strategy for ERP systems is recognized as a leading factor for ERP implementation failures (Saadé et al., 2017).

Past research suggests that an ERP system with no user satisfaction is less likely to be utilized by users and cannot generate valuable outcomes to the organization (Dezdar \& Ainin, 2011). Somers et al. (2003) maintain that a better understanding of factors that can influence user satisfaction is greatly needed in order for ERP applications to be used effectively. This study investigated three such factors that can influence user satisfaction with an ERP. All examined factors (perceived informativeness, perceived enjoyment, and attitude toward an ERP) demonstrated positive effects on satisfaction with an ERP. Accordingly, maintaining an environment and designing training workshops that highlight the information and enjoyment aspects of an ERP can boost users' perceptions of ERP informativeness and enjoyment and, eventually, improve their attitude and satisfaction with an ERP.

For research, this study makes valuable contribution to past and contemporary research. Consistent with Cohen's (2009) suggestion that the essence of informing science philosophy is to breakdown bounders that hinder the flow of knowledge from one discipline to another, this study successfully extended knowledge and models from marketing research to information systems and ERP system literature. The results of this study showed that satisfaction is a strong and significant precursor to ERP use. This finding offers additional empirical support for Delone and McLean's (2003) model of information system success, which posits that satisfaction with a system is critical to the use and success of that system. Specifically, the results reported here corroborate the notion that higher user satisfaction will lead to increased intention to use a system which ultimately increases future use of the system (Delone \& McLean, 2003). Furthermore, the results of this study are consistent with the suggestion that users' evaluation of system characteristics ("object-based beliefs") such as informativeness impacts their affective feeling toward those characteristics ("object-based attitudes") such as attitude and satisfaction, which, in turn, can predict and explain system use (Koh et al., 2010). 
Studies that combine theoretical models to examine technology use may offer more explanatory power than studies that rely on one particular theory or framework. For example, Alajmi et al. (2016) combined the UGT, the diffusion of innovation (DOI) theory, and trust theory to study factors that affect the use of Twitter. Their empirical results supported the research model and sufficiently explained why people choose to use Twitter. Likewise, this study used constructs from UGT and from Delone and McLean model of IS acceptance and examine acceptance of use of ERP systems. The results of this study provided strong support of the research model and explained the relationships among the research constructs and how they influenced ERP use. Thus, future research should consider other theories and develop research models to combine constructs from multiple theoretical frameworks to provide better understanding of factors affecting technology acceptance and use.

\section{LIMITATIONS AND FUTURE RESEARCH}

This study has a few limitations that should be recognized when interpreting the results. The first obvious limitation relates to the use of students as surrogates to ERP users in an organizational setting. However, all participants in this study reported that they were using ERP systems at their jobs. In addition, the use of student sample is consistent with previous studies in this line of research. For example, Garača (2011) used a sample of college students in a business class to examine acceptance of an ERP system. Nevertheless, future research needs to test the research model in an organizational setting to enhance the validity and generalizability of the results. Another limitation pertains to the type of the ERP system investigated. This study did not focus on specific ERP technology. Given that there are many types of ERP systems implemented across organizations, the results of this may not apply to a specific ERP environment. Accordingly, future research should target specific ERP environment or industry to determine whether the findings reported in this research can be applied to a specific ERP technology.

Finally, the research model presented and tested in this study is not meant to be a comprehensive model that incorporates all possible factors that affect ERP acceptance and use. This is evidenced by the fact that the research model explained only about $53 \%$ of the variance in ERP acceptance. Hence, a large portion of variability in ERP acceptance remains unexplained and requires further investigation. Definitely, numerous variables have been examined in past research and demonstrated significant impacts on ERP adoption. For example, organizational characteristics (Dezdar \& Ainin, 2011), management support (Plant \& Willcocks, 2007), technical resources (Nwankpa, 2015), and other individual attributes such as computer anxiety (Garača, 2011), computer self-efficacy (Scott, 2008; Shih, 2006), and culture (Hwang, 2012) are among others that should be taken into account in future studies of ERP acceptance and use. Accordingly, future research should extend the research model presented in this study by integrating other variables to provide further insights to influences individuals to accept or reject an ERP system.

\section{CONCLUSION}

The main objective of the present study was to address individual intention to use ERP systems. Drawing on UGT (Blumier \& Katz, 1974) and TRA (Ajzen \& Fishbein, 1980; Fishbein \& Ajzen, 1975), a conceptual model of the effects of ERP system gratifications, individual attitude, and satisfaction on intention to use an ERP system was developed and empirically tested. The results provide strong support of the research model and its hypothesized relationships. Perceptions of ERP informativeness and entertainment demonstrated significant effects on satisfaction with and attitude toward using ERP systems and explained about $41 \%$ of the variance in attitude toward using ERP systems. This superior explanatory power of UGT suggests that UGT is appropriate for examining and evaluating users' acceptance of ERP systems. Overall, the results of this study provide support of UGT's perspective on technology use and corroborate past studies which reported similar results (Alajmi et al., 2016). From a practical standpoint, businesses can use the UGT as a basis to develop strategies aimed at enhancing users' perceptions, gratifications, and intentions toward ERP systems. 


\section{REFERENCES}

Abdinnour-Helm, S., Lengnick-Hall, M. L., \& Lengnick-Hall, C. A. (2003). Pre-implementation attitudes and organizational readiness for implementing an enterprise resource planning (ERP) system. European Journal of Operational Research, 146, 258-273. https://doi.org/10.1016/S0377-2217(02)00548-9

Ajzen, I., \& Fishbein, M. (1980). Understanding attitudes and predicting social behavior. Englewood Cliffs, NJ: Prentice Hall.

Aladwani, A. M. (2001). Change management strategies for successful ERP implementation. Business Process Management Journal, 7(3), 266-275. https://doi.org/10.1108/14637150110392764

Alajmi, M. A., Alharbi, A. H., \& Ghuloum, H. F. (2016). Predicting the use of Twitter in developing countries: Integrating innovation attributes, uses and gratifications, and trust approaches. Informing Science: The International Journal of an Emerging Transdiscipline, 19, 215-237. https://doi.org/10.28945/3534

Al-Gahtani, S. S., \& King, M. (1999). Attitudes, satisfaction and usage: Factors contributing to each in the acceptance of information technology. Behaviour \& Information Technology, 18(4), 277-297. https://doi.org/10.1080/014492999119020

Al-Jabri, I. M., \& Roztocki, N. (2015). Adoption of ERP systems: Does information transparency matter? Telematics and Informatics, 32(2), 300-310. https://doi.org/10.1016/j.tele.2014.09.005

Amoako-Gyampah, K. (2007). Perceived usefulness, user involvement and behavioral intention: An empirical study of ERP implementation. Computers in Human Behavior, 23(3), 1232-1248. https://doi.org/10.1016/j.chb.2004.12.002

Amoako-Gyampah, K., \& Salam, A. F. (2004). An extension of the technology acceptance model in an ERP implementation environment. Information \& Management, 41(6), 731-745. https://doi.org/10.1016/j.im.2003.08.010

Blumier, J. G., \& Katz, E. (1974). The uses of mass communications: Current perspectives on gratifications research. Sage Publications.

Bryman, A., \& Cramer, D. (1994). Quantitative data analysis for social scientists. New York: Routledge.

Bueno, S., \& Salmeron, J. L. (2008). TAM-based success modeling in ERP. Interacting with Computers, 20(6), 515523. https://doi.org/10.1016/i.intcom.2008.08.003

Calisir, F., \& Calisir, F. (2004). The relation of interface usability characteristics, perceived usefulness, and perceived ease of use to end-user satisfaction with enterprise resource planning (ERP) systems. Computers in Human Behavior, 20(4), 505-515. https://doi.org/10.1016/j.chb.2003.10.004

Chen, G. M. (2011). Tweet this: A uses and gratifications perspective on how active Twitter use gratifies a need to connect with others. Computers in Human Behavior, 27(2), 755-762. https://doi.org/10.1016/j.chb.2010.10.023

Cohen, E. B. (1999). From ugly duckling to swan: Reconceptualizing information systems as a field of the discipline informing science. Journal of Computing and Information Technology, 7(3), 213-219.

Cohen, E. B. (2009). A philosophy of informing science. Informing Science: the International Journal of an Emerging Transdiscipline, 12, 1-15. https://doi.org/10.28945/425

Coulson, T., Olfman, L., Ryan, T., \& Shayo, C. (2010). Enterprise systems training strategies: Knowledge levels and user understanding. Journal of Organizational and End User Computing, 22(3), 22-39. https://doi.org/10.4018/joeuc.2010070102

Davis, F. D. (1989). Perceived usefulness, perceived ease of use, and user acceptance of information technology. MIS Quarterly, 13, 319-340. https://doi.org/10.2307/249008

Davis, F. D., Bagozzi, R. P., \& Warshaw, P. R. (1992). Extrinsic and intrinsic motivation to use computers in the workplace. Journal of Applied Social Psychology, 22(14), 1111-1132. https://doi.org/10.1111/j.15591816.1992.tb00945.x 
Delone, W. H., \& McLean, E. R. (2003). The DeLone and McLean model of information systems success: A ten-year update. Journal of Management Information Systems, 19(4), 9-30. https://doi.org/10.1080/07421222.2003.11045748

Dezdar, S., \& Ainin, S. (2011). The influence of organizational factors on successful ERP implementation. Management Decision, 49(6), 911-926. https://doi.org/10.1108/00251741111143603

Doll, W. J., \& Torkzadeh, G. (1988). The measurement of end-user computing satisfaction. MIS Quarterly, 12(2), 259-274. https://doi.org/10.2307/248851

Eighmey, J., \& McCord, L. (1998). Adding value in the information age: Uses and gratifications of sites on the World Wide Web. Journal of Business Research, 41, 187-194. https://doi.org/10.1016/S0148-2963(97)000611

Fagan, M. H., Neill, S., \& Wooldridge, B. R. (2008). Exploring the intention to use computers: An empirical investigation of the role of intrinsic motivation, extrinsic motivation, and perceived ease of use. Journal of Computer Information Systems, 48(3), 31-37.

Fishbein, M., \& Ajzen, I. (1975). Belief, attitude, intention and behavior: An introduction to theory and research. Reading, MA: Addison-Wesley.

Garača, Ž. (2011). Factors related to the intended use of ERP systems. Management-Journal of Contemporary Management Issues, 16(2), 23-42.

Hsu, P. F., Yen, H. R., \& Chung, J. C. (2015). Assessing ERP post-implementation success at the individual level: Revisiting the role of service quality. Information \& Management, 52(8), 925-942.

https://doi.org/10.1016/i.im.2015.06.009

Hung, S. Y., Tsai, J. C. A., \& Chou, S. T. (2016). Decomposing perceived playfulness: A contextual examination of two social networking sites. Information \& Management, 53(6), 698-716. https://doi.org/10.1016/j.im.2016.02.005

Hwang, Y. (2012). End user adoption of enterprise systems in eastern and western cultures. Journal of Organizational and End User Computing, 24(4), 1-17. https://doi.org/10.4018/joeuc.2012100101

Hwang, Y., \& Grant, D. (2011). Behavioral aspects of enterprise systems adoption: An empirical study on cultural factors. Computers in Human Behavior, 27(2), 988-996.

Ifinedo, P., Rapp, B., Ifinedo, A., \& Sundberg, K. (2010). Relationships among ERP post-implementation success constructs: An analysis at the organizational level. Computers in Human Behavior, 26(5), 1136-1148. https://doi.org/10.1016/i.chb.2010.03.020

Koh, C. E., Prybutok, V. R., Ryan, S. D., \& Wu, Y. (2010). A model for mandatory use of software technologies: An integrative approach by applying multiple levels of abstraction of informing science. Informing Science: The International Journal of an Emerging Transdiscipline, 13. 177-203. https://doi.org/10.28945/1326

Ku, Y. C., Chu, T. H., \& Tseng, C. H. (2013). Gratifications for using CMC technologies: A comparison among SNS, IM, and e-mail. Computers in Human Behavior, 29(1), 226-234. https://doi.org/10.1016/i.chb.2012.08.009

Leung, L. (2013). Generational differences in content generation in social media: The roles of the gratifications sought and of narcissism. Computers in Human Behavior, 29(3), 997-1006. https://doi.org/10.1016/i.chb.2012.12.028

Lim, W. M., \& Ting, D. H. (2012). E-shopping: An analysis of the uses and gratifications theory. Modern Applied Science, 6(5), 48-63. https://doi.org/10.5539/mas.v6n5p48

Longinidis, P. \& Gotzamani, K. (2009). ERP user satisfaction issues: Insights from a Greek industrial giant. Industrial Management \& Data Systems, 109(5), 628-645. https://doi.org/10.1108/02635570910957623

Luo, M. M., \& Remus, W. (2014). Uses and gratifications and acceptance of Web-based information services: An integrated model. Computers in Human Behavior, 38, 281-295. https://doi.org/10.1016/j.chb.2014.05.042

Luo, X. (2002). Uses and gratifications theory and e-consumer behaviors: A structural equation modeling study. Journal of Interactive Advertising, 2(2), 44-54. https://doi.org/10.1080/15252019.2002.10722060 
Mayeh, M., Ramayah, T., \& Mishra, A. (2016). The role of absorptive capacity, communication and trust in ERP adoption. Journal of Systems and Software, 119, 58-69. https://doi.org/10.1016/j.jss.2016.05.025

McHaney, R., Hightower, R., \& Pearson, J. (2002). A validation of the end-user computing satisfaction instrument in Taiwan. Information \& Management, 39(6), 503-511. https://doi.org/10.1016/S0378-7206(01)00119$\underline{7}$

Melone, N. P. (1990). A theoretical assessment of the user-satisfaction construct in information systems research. Management Science, 36(1), 76-91. https://doi.org/10.1287/mnsc.36.1.76

Mitra, P., \& Mishra, S. (2016). Behavioral aspects of ERP implementation: A conceptual review. Interdisciplinary Journal of Information, Knowledge, and Management, 11, 17-30. https://doi.org/10.28945/3402

Mun, Y. Y., \& Hwang, Y. (2003). Predicting the use of web-based information systems: Self-efficacy, enjoyment, learning goal orientation, and the technology acceptance model. International Journal of Human-Computer Studies, 59(4), 431-449. https://doi.org/10.1016/S1071-5819(03)00114-9

Nah, F., Tan, X., \& Teh, S. (2004). An empirical investigation on end-users' acceptance of enterprise systems. Information Resources Management Journal, 17(3), 32-53. https://doi.org/10.4018/irmj.2004070103

North, D., Johnston, K., \& Ophoff, J. (2014). The use of mobile phones by South African university students. Issues in Informing Science and Information Technology, 11, 115-138. https://doi.org/10.28945/1984

Nwankpa, J. K. (2015). ERP system usage and benefit: A model of antecedents and outcomes. Computers in Human Behavior, 45, 335-344. https://doi.org/10.1016/j.chb.2014.12.019

Petersen, C., \& Johnston, K. A. (2015). The impact of social media usage on the cognitive social capital of university students. Informing Science: the International Journal of an Emerging Transdiscipline, 18, 1-30. https://doi.org/10.28945/2160

Plant, R., \& Willcocks, L. (2007). Critical success factors in international ERP implementations: A case research approach. Journal of Computer Information Systems, 47(3), 60-70.

Premkumar, G., \& Bhattacherjee, A. (2008). Explaining information technology usage: A test of competing models. Omega, 36(1), 64-75. https://doi.org/10.1016/j.omega.2005.12.002

Ram, J., Corkindale, D., \& Wu, M. L. (2013). Enterprise resource planning adoption: Structural equation modeling analysis of antecedents. Journal of Computer Information Systems, 54(1), 53-65. https://doi.org/10.1080/08874417.2013.11645671

Ruggiero, T. E. (2000). Uses and gratifications theory in the 21st century. Mass Communication \& Society, 3(1), 337. https://doi.org/10.1207/S15327825MCS0301 02

Saadé, R. G., Nijher, H., \& Sharma, M. C. (2017). Why ERP implementations fail-A grounded research study. Proceedings of the Informing Science + Information Technology Education Conference, July 31 - August 5, Ho Chi Minh City (Saigon), Vietnam. https://doi.org/10.28945/3762

Scott, J. E. (2008). Technology acceptance and ERP documentation usability. Communications of the ACM, 51(11), 121-124. https://doi.org/10.1145/1400214.1400239

Shao, G. (2009). Understanding the appeal of user-generated media: A uses and gratification perspective. Internet Research, 19(1), 7-25. https://doi.org/10.1108/10662240910927795

Shih, Y. Y. (2006). The effect of computer self-efficacy on enterprise resource planning usage. Behaviour \& Information Technology, 25(5), 407-411. https://doi.org/10.1080/01449290500168103

Shih, Y. Y., \& Huang, S. S. (2009). The actual usage of ERP systems: An extended technology acceptance perspective. Journal of Research and Practice in Information Technology, 41(3), 263.

Somers, T. M., Nelson, K., \& Karimi, J. (2003). Confirmatory factor analysis of the end-user computing satisfaction instrument: Replication within an ERP domain. Decision Sciences, 34(3), 595-621. https://doi.org/10.1111/j.1540-5414.2003.02428.x

Stafford, T. F., Stafford, M. R., \& Schkade, L. L. (2004). Determining uses and gratifications for the Internet. Decision Sciences, 35(2), 259-288. https://doi.org/10.1111/j.00117315.2004.02524.x 
Sternad, S., Gradisar, M., \& Bobek, S. (2011). The influence of external factors on routine ERP usage. Industrial Management \& Data Systems, 111(9), 1511-1530. https://doi.org/10.1108/02635571111182818

Webster, J., \& Martocchio, J. J. (1992). Microcomputer playfulness: Development of a measure with workplace implications. MIS Quarterly, 16(2), 201-226. https://doi.org/10.2307/249576

Wu, J. H., Wang, S. C., \& Tsai, H. H. (2010). Falling in love with online games: The uses and gratifications perspective. Computers in Human Behavior, 26(6), 1862-1871. https://doi.org/10.1016/i.chb.2010.07.033

Zabukovsek, S. S., \& Bobek, S. (2013). TAM-based external factors related to ERP solutions acceptance in organizations. International Journal of Information Systems and Project Management, 1(4), 25-38.

Zouine, A., \& Fenies, P. (2014). The critical success factors of the ERP system project: A meta-analysis methodology. Journal of Applied Business Research, 30(5), 1407. https://doi.org/10.19030/jabr.v30i5.8796

\section{BIOGRAPHY}

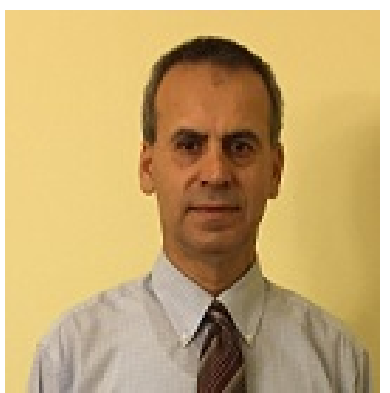

Dr. Bassam Hasan is an Associate Professor of Information Systems in the Information Technology and Operations Management (IOTM) Department at The University of Toledo. Dr. Hasan's research interests include knowledge management, ERP implementation and success, ecommerce, and end-user training. Dr. Hasan's research has been published in numerous IS journals such as Information \& Management, Journal of Organizational and End User Computing, Computers in $\mathrm{Hu}-$ man Behavior, Journal of Information and Knowledge Management. 